\title{
THE THANKSGIVING MEETING IN PASADENA
}

The two hundred seventy-fourth regular meeting of the Society was held on Friday, November 29, 1929, at the California Institute of Technology. Sessions were held in the morning and in the afternoon. The attendance included the following thirty-nine members of the Society:

O. W. Albert, Basoco, Harry Bateman, Clifford Bell, E. T. Bell, Bernstein, Birchby, Blichfeldt, Daus, Duncan, Elder, Engstrom, Garver, Glazier, Graesser, J. G. Hardy, M. W. Haskell, E. R. Hedrick, G. H. Hunt, Glenn James, B. W. Jones, L. S. Kennison, D. N. Lehmer, G. F. McEwen, W. E. Mason, Michal, Noble, T. M. Putnam, P. G. Robinson, Stager, Steed, Van Buskirk, Morgan Ward, Wear, Whiting, W. M. Whyburn, A. R. Williams, Wolfe, Worthington.

The meeting was presided over at different times by President E. R. Hedrick, Professor M. W. Haskell, and Professor E. T. Bell.

There was no meeting of the Council or of the Trustees of the Society.

A luncheon for members and their guests was held between sessions at the Maryland Hotel.

At the request of the Program Committee, Professor M. W. Haskell, of the University of California, delivered an address entitled Autopolar configurations in the plane and in space.

The titles and cross-references to the abstracts* of the papers read at this meeting follow below. The papers whose abstract numbers are accompanied by the letter $t$ were read by title. Dr. Pall was introduced by Professor E. T. Bell, and Professor Uspensky and Mr. Ingram were introduced by Professor Hedrick.

1. Autopolar configurations in the plane and in space, by Professor M. W. Haskell. (Abstract No. 36-1-44.)

2. Generalized Riccati differential equations, by Professor W. M. Whyburn. (Abstract No. 36-1-45-t.)

\footnotetext{
* See the footnote on page 6 .
} 
3. On related difference and differential systems, by Professor W. M. Whyburn. (Abstract No. 36-1-46.)

4. Generalizations of Liouville's theorem and allied theorems, by Professor E. R. Hedrick. (Abstract No. 36-1-47.)

5. On certain quartic surfaces which are the envelopes of two systems of conicoids, by Dr. A. R. Williams. (Abstract No. 36-1-48.)

6. Three degeneracies in the theory of ternary quadratic forms, by Professor E. T. Bell. (Abstract No. 36-1-49.)

7. A triple of ternary quadratic forms, by Professor E. T. Bell. (Abstract No. 36-1-50.)

8. On certain quinary and senary quadratic forms, by Professor E. T. Bell. (Abstract No. 36-1-51.)

9. On Franklin magic squares, by Professor D. N. Lehmer. (Abstract No. 36-1-52.)

10. A system of integral equations implying and implied by a system of first order linear differential equations, by $\mathrm{Mr} . \mathrm{W}, \mathrm{H}$. Ingram. (Abstract No. 36-1-53.)

11. Systems of integral equations and their Fredholm solutions, by Mr. W. H. Ingram. (Abstract No. 36-1-54.)

12. Application of the theory of integral equations to the theory of the electrical transmission line, by Mr. W. H. Ingram. (Abstract No. 36-1-55.)

13. On the transformation which reduces the Brioschi normal quintic to a general principal quintic, by Professor Raymond Garver. (Abstract No. 36-1-56.)

14. Concerning polynomial functions with certain properties, by Professor Raymond Garver. (Abstract No. 36-1-57-t.)

15. Newton's idea of God in the different editions of the Principia, by Professor Florian Cajori. (Abstract No. 36-1-58-t.)

16. On the representations of a constant times a square as the sum of an odd number of squares, by Dr. Gordon Pall. (Abstract No. 36-1-59.)

17. On certain irregular ternary forms with cross products, by Dr. B. W. Jones. (Abstract No. 36-1-60.)

18. In-and circumscribed sets of planes to space curves, by Dr. Clifford Bell. (Abstract No. 36-1-61.)

19. On the ideal theory of Zolotarev, by Dr. H. T. Engstrom. (Abstract No. 36-1-62.) 
20. Fourier expansions of doubly periodic functions of the third kind, by Dr. J. D. Elder. (Abstract No. 36-1-63.)

21. The characteristic number of a sequence of integers satisfying a linear recursion relation, by Dr. Morgan Ward. (Abstract No. 36-1-64.)

22. Note on a table of linear forms, by Professor P. H. Daus. (Abstract No. 36-1-65.)

23. A simple proof of the theorem on the limit of probability, by Professor J. V. Uspensky. (Abstract No. 36-1-66.)

B. A. Bernstein, Associate Secretary 